TI 2002-097/4

Tinbergen Institute Discussion Paper

\title{
A Dynamic Utility Maximization Model for Product Category Consumption
}

\author{
Rutger van Oest \\ Philip Hans Franses \\ Richard Paap
}


Tinbergen Institute

The Tinbergen Institute is the institute for economic research of the Erasmus Universiteit Rotterdam, Universiteit van Amsterdam and

Vrije Universiteit Amsterdam.

Tinbergen I nstitute Amsterdam

Keizersgracht 482

1017 EG Amsterdam

The Netherlands

Tel.: +31.(0)20.5513500

Fax: $\quad+31 .(0) 20.5513555$

Tinbergen Institute Rotterdam

Burg. Oudlaan 50

3062 PA Rotterdam

The Netherlands

Tel.: $\quad+31 .(0) 10.4088900$

Fax: $\quad+31 .(0) 10.4089031$

Most TI discussion papers can be downloaded at

http://www.tinbergen.nl 


\title{
A Dynamic Utility Maximization Model for Product Category Consumption
}

\author{
Rutger van Oest* \\ Tinbergen Institute \\ Erasmus University Rotterdam \\ Philip Hans Franses \\ Econometric Institute \\ Erasmus University Rotterdam \\ Richard Paap \\ Econometric Institute \\ Erasmus University Rotterdam
}

*Corresponding author: Tinbergen Institute, H16-32, Erasmus University Rotterdam, P.O. Box 1738, 3000 DR Rotterdam (vanoest@few.eur.nl). We wish to thank Pradeep Chintagunta, Bas Donkers, Dennis Fok, Lennart Hoogerheide, Peter Rossi, and participants at the Marketing Science 2002 (Edmonton) Conference for their useful comments. Additionally, Dennis Fok is thanked for his help with the data. The results in the paper have been obtained using Ox v2.20 (Doornik 1998). 


\title{
A Dynamic Utility Maximization Model for Product Category Consumption
}

\begin{abstract}
It is conceivable that the "whether to buy" and "how much to buy" decisions in the purchasing process of households are influenced by the inventory process. In this paper we therefore put forward a model for consumption, where we rely on established economic theory. We incorporate this model in a model for purchase behavior. Our consumption specification, which is derived from utility maximization principles, is more flexible than an ad hoc approach, which has recently been proposed in the literature. We illustrate our model for yogurt purchases, and show that our model yields important additional and useful insights. One such insight is that promotion anticipation behavior turns out not only to occur in the purchasing process, but also in the consumption process.
\end{abstract}

\section{Keywords}

consumption function, inventory, utility maximization, promotion anticipation 


\section{Introduction}

When a household contemplates a purchase from a product category, the inventory level at hand is an important decision variable. This inventory level influences both the "whether to buy" decision, and the "how much to buy" decision. A low inventory level increases the risk of incurring stock-out costs. For example, Gönül and Srinivasan (1996) demonstrate that these stock-out costs can be substantial. This provides households with an incentive to keep the inventory level on track by making purchases.

A small inventory stock reduces the flexibility of a household in two ways. First, freedom in consumption is restricted, as consumption until the next purchase occasion cannot exceed available inventory. Second, a small inventory reduces the opportunities to anticipate future promotional activities, as stock-out costs may outweigh the promotional gains. On the other hand, a large inventory stock may lead to high holding costs. So, each household has to make a tradeoff between consumption flexibility and inventory holding costs. This tradeoff influences the subsequent purchase incidence decision and the purchase quantity decision.

The inventory level of a household results from past purchases and past consumption. As available inventory is typically not observed in commonly available scanner data, it is usually taken into account by postulating some underlying process. In the literature, a popular assumption is that the consumption rate of a household is constant over time, see Bucklin and Gupta (1992), Bucklin, Gupta and Siddarth (1998), Chintagunta (1993), Gupta (1988), Mela, Jedidi and Bowman (1998), Neslin, Henderson and Quelch (1985), among others. However, this convenient assumption might not always be appropriate. As an alternative, Ailawadi and Neslin (1998) therefore consider a flexible consumption specification in which consumption depends on the available inventory stock. They consider two product categories, and their findings are as follows. Although the relation between inventory and consumption turns out to be weak for ketchup, this is certainly not the case for yogurt. For the latter product category, strong evidence is found that a 
higher inventory level results in more consumption. So, the assumption of a constant consumption rate apparently seems reasonable for ketchup, but not for yogurt. The observed difference between ketchup and yogurt can be explained by the holding costs and consumption opportunities of the two product categories. For yogurt, the holding costs are higher due to higher perishability. Further, there are more consumption possibilities, as yogurt might be consumed at virtually each moment of the day.

In this paper, we also elaborate on the consumption process, as is done in Ailawadi and Neslin (1998). The main distinction, though, is that we aim to take a more formal approach, guided by economic theory. In Section 2, we put forward our model of consumption. We demonstrate that our model does not only make more sense from an economic point of view, but we also show that the model allows for much more flexibility in household behavior. In Section 3, we incorporate it in a model for purchases. In Section 4, we illustrate our model for yogurt purchases, and we report that our model gives more insights into the purchase process of households. We find some evidence that promotion anticipation does not only exist in purchase behavior, but also in consumption behavior. We further show that our model performs better, both in-sample as out-of-sample, than the model which includes an ad hoc specification for the consumption process. In Section 5, we conclude with some suggestions for further research.

\section{A model of consumption}

In this section, we put forward the components of our model for product category consumption. Next, we compare it with an alternative model, currently available in the marketing literature.

\subsection{Our model}

We assume that households are utility maximizers. As most consumption goods can be stored and hence do not need to be consumed instantaneously, we adopt a 
dynamic perspective. Hence, we assume that households are forward-looking with some finite planning horizon. For a given available inventory, more consumption today implies that less is left for consumption in the near future. So, households face a dynamic optimization problem. In our model, each household chooses its consumption levels such that total discounted utility, which is achieved until the planning horizon, is maximized under the condition that total consumption cannot exceed available inventory. The considered planning horizon is allowed to vary over households, and it depends on the particular situation that a household faces. The above components will be formalized in the sequel of this section.

\section{Utility}

We impose that households have a constant relative risk aversion (CRRA) utility function. Household $i$ derives instantaneous utility, defined as

$$
u\left(C_{i, t}\right)=\frac{C_{i, t}^{1-\theta}}{1-\theta}, \quad 0<\theta<1
$$

from consuming $C_{i, t}$ units at time $t$. The CRRA utility specification is frequently used in the economic literature, see Romer (1996) among many others. It involves one curvature parameter $\theta$, which can be interpreted as a measure of risk aversion. For $\theta$ close to 0 , the utility function is essentially linear. When the value of $\theta$ increases, the utility function becomes more curved. Households with a large curvature parameter $\theta$ have an incentive to smooth their consumption paths over time. This is because a loss in consumption is penalized more severely in terms of utility than a gain of the same magnitude is rewarded.

If $T_{i, t}$ denotes the planning horizon for household $i$ at time $t$, total consumption utility until this planning horizon is given by

$$
\sum_{s=t}^{t+T_{i, t}} \frac{1}{(1+\rho)^{s-t}} u\left(C_{i, s}\right), \quad \rho>0
$$

where $\rho$ is a discount rate for time. Besides direct time preferences, this parameter may also account for holding costs. For example, $\rho$ can be expected to be larger for, say, yogurt than for ketchup. We note that a household with a smaller discount rate 
$\rho$ has a larger incentive to smooth consumption over time, as the value of future consumption decreases more slowly.

\section{Consumption path}

Household $i$ maximizes its discounted consumption utility until planning horizon $T_{i, t}$, given that total consumption $\sum_{s=t}^{t+T_{i, t}} C_{i, s}$ cannot exceed the available inventory $S_{i, t}$. The optimal consumption path is thus defined by

$$
\left(C_{i, t}, \ldots, C_{i, t+T_{i, t}}\right)=\underset{\left\{\tilde{C}_{i, s}\right\}_{s=t}^{t+T_{i, t}}}{\arg \max }\left\{\sum_{s=t}^{t+T_{i, t}} \frac{1}{(1+\rho)^{s-t}} u\left(\tilde{C}_{i, s}\right): \sum_{s=t}^{t+T_{i, t}} \tilde{C}_{i s} \leq S_{i, t}\right\} .
$$

In Appendix A, we derive that from (1), (2) and (3), it follows that the optimal consumption path for household $i$ is given by

$$
\begin{aligned}
C_{i, t} & =S_{i, t} \frac{1-\nu}{1-\nu^{T_{i, t}+1}} \quad \text { with } \quad \nu=(1+\rho)^{-\frac{1}{\theta}}, \\
C_{i, t+s} & =\nu^{s} C_{i, t}, \quad s=1, \ldots, T_{i, t} .
\end{aligned}
$$

At time $t$, the household consumes the optimal amount (4), but the remaining part of the consumption path, that is, (5), is ignored.

\section{Planning horizon}

For the unobserved planning horizon $T_{i, t}$ in (4), one may expect that it varies over households and that it depends on the particular situation that a household faces. For example, if the inventory level is very low, then it does not make sense to plan consumption of this inventory stock far ahead. We assume that the planning horizon is proportional to the time period, which is needed to deplete the current inventory stock when consumption is at the household's average level, that is,

$$
T_{i, t}=\exp \left(M_{i, t}{ }^{\prime} \delta\right) \frac{S_{i, t}}{\bar{C}_{i}}
$$

where $\exp \left(M_{i, t}{ }^{\prime} \delta\right)$ is the proportionality factor and $\bar{C}_{i}$ denotes the average consumption rate of household $i$. The proportionality factor contains a scaling parameter and it may depend on marketing variables $M_{i, t}$ in order to allow for promotion anticipation effects. For example, Gönül and Srinivasan (1996) show that coupon 
anticipation can be relevant and they find that the time period until the next coupon promotion is expected to be longer when a coupon is available at the last purchase occasion. Such expectations provide anticipating households with an incentive to stockpile after a coupon promotion, so that they can comfortably wait for the next coupon promotion without having to incur stock-out costs. However, a drawback of stockpiling is that it may result in high inventory holding costs. As a consequence, households may not only want to adjust their purchase pattern, but possibly also their consumption pattern. This latter adjustment is captured in our model by allowing that promotion anticipation results in a longer consumption planning horizon through the proportionality factor $\exp \left(M_{i, t}{ }^{\prime} \delta\right)$. Furthermore, the parameter for the intercept in $M_{i, t}$, that is, the scaling parameter, can be expected to be related to the stock-out costs for the product category. If stock-out costs are high, households want to reduce the risk of stock-out. This can be achieved by either maintaining a larger inventory, leading to higher holding costs, or by planning consumption further ahead. A large value for the scaling parameter in the planning horizon may be an indication that stock-out costs are high.

\section{Consumption model}

By substituting the planning horizon (6) into (4), we obtain our consumption function, which is given by

$$
C_{i, t}=S_{i, t} \frac{1-\nu}{1-\nu \frac{\exp \left(M_{\left.i, t^{\prime} \delta\right) S_{i, t}+\bar{C}_{i}}\right.}{\bar{C}_{i}}} \quad \text { with } \quad \nu=(1+\rho)^{-\frac{1}{\theta}}
$$

To complete the model, we define the inventory variable, which influences the purchase incidence decision and the purchases quantity decision, by

$$
S_{i, t}=S_{i, t-1}+Q_{i, t-1}-C_{i, t-1}
$$

where $Q_{i, t-1}$ is the quantity purchased at time $t-1$. In words, available inventory at time $t$ equals available inventory at time $t-1$ plus the quantity purchased at time $t-1$ minus consumption at time $t-1$. The inventory process follows from combining (8) with (7). 


\subsection{Comparison with another approach}

In the previous subsection, we put forward a model for category consumption at the household level. This model differs in certain respects from a model, currently available in the literature.

Our consumption function in (7) is increasing in both the inventory level $S_{i, t}$ and the household's average consumption rate $\bar{C}_{i}$. These rather plausible properties are proved in Appendix B. Further, the explicit restriction that a household cannot consume more than its available inventory ensures that inventory is never negative, which is another desirable property.

In order to better illustrate the properties of our consumption function, we first consider the consumption specification of Ailawadi and Neslin (1998), which is given by

$$
C_{i, t}=S_{i, t} \frac{\bar{C}_{i}}{\bar{C}_{i}+S_{i, t}^{\phi}}
$$

Note that this specification is not based on economic theory. This specification guarantees that inventory cannot become negative and that consumption is increasing in the household's average consumption rate $\bar{C}_{i}$. Moreover, consumption is also increasing in the inventory level $S_{i, t}$, as long as the parameter $\phi$ is smaller than 1 .

Figure 1 displays the consumption function of Ailawadi and Neslin (1998) for a household with an average consumption rate $\bar{C}_{i}=5$ for different values of $\phi$. It is seen that for parameter values $\phi$ close to 1 , the constant consumption rate assumption is mimicked, as dependence of consumption on the inventory level is small. The smaller the value of $\phi$, the stronger the dependence becomes. For $\phi$ small enough, consumption coincides with the inventory level, that is, the entire inventory is consumed instantaneously. It is important to stress here that the specification of

Ailawadi and Neslin (1998) implies that consumption equals $\frac{\bar{C}_{i}}{\bar{C}_{i}+1}$ when the inventory stock consists of exactly a single unit. This holds for all values of $\phi$, and this is also clearly visualized by the graphs in Figure 1. As the consumption function only contains one parameter, consumption lines cannot intersect elsewhere, and hence in that respect the model is rather inflexible. 
Insert Figure 1 about here.

Insert Figure 2 about here.

We now turn to our consumption function in (7). Figure 2 again displays the consumption function for a household with an average consumption rate $\bar{C}_{i}=5$ for different parameter values. Disregarding anticipation effects, the planning horizon only contains the factor $\exp (\delta)$. The first two consumption lines are obtained by setting the parameter $\nu$, which is a function of the curvature parameter $\theta$ and the discount rate $\rho$, at value 0.98 . It can be seen that a large value for $\nu$ results in a relatively flat consumption function, and hence a constant consumption rate assumption may be reasonable. As $\nu=(1+\rho)^{-\frac{1}{\theta}}$, large values for $\nu$ can be obtained by a low discount rate $\rho$, by a large curvature parameter $\theta$, or by both. As indicated before, this is rather plausible, as both conditions provide households with an incentive to smooth consumption over time. Furthermore, as the consumption line with $\delta=\ln (0.4)$ is located above the consumption line with $\delta=0$, it is seen that a shorter time horizon leads to a higher consumption level. Again, this is plausible.

The third consumption line in Figure 2 shows that essentially the whole inventory stock is consumed instantaneously when $\nu$ is small, that is, when the discount rate $\rho$ is large, the curvature parameter $\theta$ is small, or both. Finally, the fourth consumption line describes a consumption pattern such that approximately half the available inventory is consumed each time.

These graphs demonstrate the flexibility of our consumption specification, as consumption lines can intersect at about any inventory level. For example, the first and the fourth consumption lines intersect at an inventory level of approximately 12 units. In sum, not only is our model based on economic theory, it is also more attractive from a practical perspective.

\section{The purchase decision model}

Our consumption model, which we derived using dynamic utility maximization principles, can be incorporated into a purchase decision model in the usual way. A pur- 
chase decision consists of three components, that is, the purchase incidence decision, the brand choice decision and the purchase quantity decision.

\subsection{Brand choice}

For the brand choice decision, we consider the conditional logit model, initially proposed by McFadden (1973). Conditional on purchase incidence, the probability that household $i$ selects brand $j \in(1, \ldots, J)$ at time $t$ is given by

$$
\operatorname{Pr}\left(B_{i, t}=j \mid Y_{i, t}=1\right)=\frac{\exp \left(U_{i, j, t}\right)}{\sum_{k=1}^{J} \exp \left(U_{i, k, t}\right)},
$$

where $Y_{i, t}$ is an indicator variable for purchase incidence, $B_{i, t}$ is the brand choice variable and $U_{i, j, t}$ is a linear function of variables specific for brand $j$. We define $U_{i, j, t}$ as

$$
U_{i, j, t}=\beta_{0, j}^{B}+\beta_{1}^{B} B L_{i, j, t}+\beta_{2}^{B} P_{i, j, t}+\beta_{3}^{B} P R_{i, j, t}
$$

where $B L_{i, j, t}$ is a brand loyalty variable which can be measured as is done in Guadagni and Little (1983), $P_{i, j, t}$ is the price per unit, and $P R_{i, j, t}$ is an indicator variable for promotion (a feature or display).

The brand loyalty variable $B L_{i, j, t}$ is an exponentially weighted average of past brand choice. If a purchase is made at shopping trip $t$, this brand loyalty variable becomes

$$
B L_{i, j, t}=\alpha B L_{i, j, t-1}+(1-\alpha) I\left\{b_{i, t-1}=j\right\},
$$

where $I\left\{b_{i, t-1}=j\right\}$ is a $0 / 1$-variable indicating whether brand $j$ has been purchased at the previous purchase occasion $t-1$. The brand loyalty variable for brand $j$ is initialized at the first purchase occasion by setting it at $\alpha$ if the brand was purchased, and setting it at $\frac{1-\alpha}{J-1}$ otherwise. In our analysis below, we estimate the carry-over parameter $\alpha$.

\subsection{Purchase incidence}

For the purchase incidence decision, we consider the binary logit model. The purchase incidence probability for household $i$ at shopping trip $t$ is given by

$$
\operatorname{Pr}\left(Y_{i, t}=1\right)=\frac{\exp \left(V_{i, t}\right)}{1+\exp \left(V_{i, t}\right)}
$$


where $V_{i, t}$ is a linear function of explanatory variables. We define the latter by

$$
V_{i, t}=\beta_{0}^{I}+\beta_{1}^{I}\left(S_{i, t}-\bar{S}_{i}\right)+\beta_{2}^{I} C V_{i, t}+\beta_{3}^{I} Y_{i, t-1}+\beta_{4}^{I} \bar{C}_{i}
$$

where $\left(S_{i, t}-\bar{S}_{i}\right)$ is the inventory level in deviation from the household's average inventory level, $C V_{i, t}$ is the so-called category value, $Y_{i, t-1}$ is an indicator variable for purchase incidence at the previous shopping trip $t-1$, and $\bar{C}_{i}$ is the household's average consumption rate.

The category value variable is defined by

$$
C V_{i, t}=\ln \left(\sum_{k=1}^{J} \exp \left(U_{i, k, t}\right)\right)
$$

which can be interpreted as the maximum expected utility level that can be achieved from the brand choice decision, see Ben-Akiva and Lerman (1985). The average consumption rate $\bar{C}_{i}$ is determined as the number of units purchased during the initialization period, divided by the number of time periods. The inventory variable $S_{i, t}$, which can be constructed using (7) and (8), is initialized by setting it at the household's average purchase quantity $\bar{Q}_{i}$, which is computed from the same initialization period as $\bar{C}_{i}$. This initialization approach is also pursued in Neslin, Henderson and Quelch (1985) and Gupta (1988), among others.

\subsection{Purchase quantity}

Conditional on purchase incidence and brand choice, the purchase quantity decision is modeled using a truncated Poisson regression model, excluding 0 as a possible outcome. This model takes into account that packaged goods are purchased in small discrete amounts and that the quantity purchased consists of at least one unit. The truncated Poisson regression model is also used by Ailawadi and Neslin (1998) and Bucklin, Gupta and Siddarth (1998), among others. The purchase quantity probability is given by

$$
\operatorname{Pr}\left(Q_{i, t}=q \mid Y_{i, t}=1, B_{i, t}=j\right)=\frac{\lambda_{i, j, t^{q}}}{\left[\exp \left(\lambda_{i, j, t}\right)-1\right] q !},
$$

where

$$
\lambda_{i, j, t}=\exp \left(\beta_{0}^{Q}+\beta_{1}^{Q}\left(S_{i, t}-\bar{S}_{i}\right)+\beta_{2}^{Q} \bar{Q}_{i}+\beta_{3}^{Q} P_{i, j, t}+\beta_{4}^{Q} P R_{i, j, t}\right)
$$


is the intensity parameter. The explanatory variables are the inventory level in deviation from the household's average inventory level, the household's average purchase quantity, the price of the selected brand, and an indicator variable for promotion.

\subsection{Estimation}

The parameters of the purchase decision model can be estimated using maximum likelihood [ML]. The likelihood function for the joint model is given by

$$
\begin{aligned}
L= & \prod_{i} \prod_{t}\left[\left(\frac{\exp \left(V_{i, t}\right)}{1+\exp \left(V_{i, t}\right)}\right)^{y_{i, t}}\left(\frac{1}{1+\exp \left(V_{i, t}\right)}\right)^{\left(1-y_{i, t}\right)}\right. \\
& {\left.\left[\prod_{j}\left(\frac{\exp \left(U_{i, j, t}\right)}{\sum_{k=1}^{J} \exp \left(U_{i, k, t}\right)} \frac{\lambda_{i, j, t}{ }^{q_{i, t}}}{\left[\exp \left(\lambda_{i, j, t}\right)-1\right] q_{i, t} !}\right)^{I\left\{b_{i, t}=j\right\}}\right]\right], }
\end{aligned}
$$

where $y_{i, t}, b_{i, t}$ and $q_{i, t}$ are realizations of the purchase incidence variable $Y_{i, t}$, the brand choice variable $B_{i, t}$ and the purchase quantity variable $Q_{i, t}$, respectively. The corresponding log-likelihood function can be written as

$$
\ln L=\sum_{i} \sum_{t}\left[C O N_{I, i, t}+C O N_{B, i, t}+C O N_{Q, i, t}\right]
$$

where, upon using that $\sum_{j} I\left\{b_{i, t}=j\right\}=y_{i, t}$ and $y_{i, t} \ln \left(q_{i, t} !\right)=\ln \left(q_{i, t} !\right)$, the contributions are

$$
\begin{aligned}
C O N_{I, i, t} & =y_{i, t} V_{i, t}-\ln \left(1+\exp \left(V_{i, t}\right)\right), \\
C O N_{B, i, t} & =\sum_{j}\left(I\left\{b_{i, t}=j\right\} U_{i, j, t}\right)-y_{i, t} \ln \left(\sum_{k=1}^{J} \exp \left(U_{i, k, t}\right)\right), \\
C O N_{Q, i, t} & =\sum_{j}\left(I\left\{b_{i, t}=j\right\}\left[q_{i, t} \ln \left(\lambda_{i, j, t}\right)-\ln \left(\exp \left(\lambda_{i, j, t}\right)-1\right)\right]\right)-\ln \left(q_{i, t} !\right),
\end{aligned}
$$

decomposed by purchase incidence, brand choice and purchase quantity.

Following Ailawadi and Neslin (1998), the model parameters are estimated in two stages. The brand choice component is estimated before the purchase incidence and purchase quantity components. Numerical techniques have to be used to get the ML parameter estimates. Details about the program can be obtained from the corresponding author. 


\section{An empirical illustration}

In this section, we apply our dynamic utility consumption specification to an A.C. Nielsen scanner panel data set on yogurt purchases. We interpret the consumption parameters and we compare the performance of the consumption function with the consumption specification of Ailawadi and Neslin (1998).

\subsection{Data}

In the application, we consider A.C. Nielsen scanner panel data on yogurt purchases in the Sioux Falls, South Dakota, market. The considered period consists of 92 weeks, and it runs from November 1986 to August 1988. We focus on six brands, which together account for more than $75 \%$ of the category sales in units. These brands are Dannon, Nordica, QC, W.B.B., Weight Watchers and Yoplait.

The first 46 weeks of the considered period are used for initialization, while the remaining 46 weeks are used for both estimation and out-of-sample model validation. Only households which make at least one shopping trip every two weeks and which have at least four purchase incidences in the 46-week initialization period are considered in the analysis. The latter condition is used in order to avoid serious distortions due to improper initialization. By doing so, we end up with 147 households, 15054 shopping trips and 2895 purchase incidences. The estimation sample consists of $80 \%$ of these households, and the remaining $20 \%$ is assigned to a hold-out sample. In our analysis, purchase quantity, inventory and consumption are measured in multiples of six ounces.

\subsection{Estimation results}

We estimate three implementations of the purchase decision model, described in the previous section. The first of these three models incorporates our consumption specification while allowing for promotion anticipation effects in consumption planning. This is done by including price and promotion as explanatory variables in the planning horizon. Since only one price and one promotion variable can be consid- 
ered in the consumption process, we weight the price and promotion variables of the various brands with the corresponding market shares in the initialization period. We note that market share weights are preferred over, for example, brand loyalty weights. The reason is that market share weights are the same for all households, whereas brand loyalty weights are not. For example, a consequence of weighting with brand loyalty would be that a household, preferring cheaper brands, ends up with a lower weighted price than a household which prefers more expensive brands. As promotion anticipation in consumption would mean that a lower price results in a longer planning horizon, the model would imply that households, preferring cheaper brands, plan consumption further ahead. Clearly, we do not want to impose this. So, it is desirable that the weights in this first model are the same for all households, which makes market share weights attractive. We note that, in the model, the weighted price is considered in deviation from its average.

The second implementation of the purchase decision model is based on our consumption specification without allowing for promotion effects, that is, the planning horizon now only contains an intercept. Finally, the third implementation considers the consumption specification of Ailawadi and Neslin (1998). The response parameter estimates can be found in Table 1.

\section{Insert Table 1 about here.}

It is seen from the table that all response parameters for all three models are significant at a $5 \%$ level. With the exception of promotion in the purchase quantity part, all coefficients have the expected sign. An explanation for the somewhat surprising sign of promotion might be that a feature or display induces brand switching. The risk involved in this brand switching might make a small purchase quantity plausible. Table 1 further shows that the inventory level is indeed an important decision variable for the purchase incidence and purchase quantity decisions.

\section{Insert Table 2 about here.}

Table 2 reports the estimated consumption parameters, which determine the inventory level. We estimate the parameter $\phi$ in the consumption specification 
of Ailawadi and Neslin (1998) at -0.775 which is quite in accordance with their estimated value of -0.65 . In our consumption specifications, the parameter $\nu=(1+$ $\rho)^{-\frac{1}{\theta}}$ is estimated at about 0.80 . It is further seen that "under normal circumstances" the consumption planning horizon is approximately equal to the inventory depletion time $\frac{S_{i, t}}{\bar{C}_{i}}$, as the intercept parameter is close to 0 .

The signs of the price and promotion variables in the planning horizon are particularly interesting, as they indicate that promotion anticipation effects exist in consumption planning for yogurt. The price coefficient is significant at a $10 \%$ level. So, promotion anticipation does not only occur in purchase behavior (Gönül and Srinivasan 1996), but there is also some evidence that it occurs in consumption behavior.

\section{Insert Figure 3 about here.}

For illustrative purposes, we display the two estimated consumption functions without promotion anticipation effects in Figure 3. This is done for "the average household", having a consumption rate of 0.136 units per day. The graph shows that the patterns of our consumption function and the consumption function of Ailawadi and Neslin (1998) are quite different.

\section{Insert Table 3 about here.}

We next consider the statistical fit, which is reported in Table 3. A useful measure for comparing non-nested models is the adjusted likelihood ratio index, which is defined by

$$
\bar{\rho}^{2}=1-\frac{\ln L-K}{\ln L_{0}}
$$

where $K$ is the number of parameters, $\ln L$ is the $\log$-likelihood value of the model, and $\ln L_{0}$ is the log-likelihood value of the corresponding null-model with only intercepts. It is seen from the table that this measure of statistical fit is larger for our two models than for the model of Ailawadi and Neslin (1998). In order to determine whether our consumption function performs significantly better in-sample, 
we consider a formal test, which is outlined in Ben-Akiva and Lerman (1985). Under the null hypothesis that the model of Ailawadi and Neslin (1998) is correct, it asymptotically holds that

$$
\operatorname{Pr}\left(\bar{\rho}_{2}^{2}-\bar{\rho}_{1}^{2}>z\right) \leq \Phi\left(-\sqrt{-2 z \ln L_{0}+\left(K_{2}-K_{1}\right)}\right)
$$

where $\bar{\rho}_{1}^{2}$ and $\bar{\rho}_{2}^{2}$ are the adjusted likelihood ratio indexes for the model of Ailawadi and Neslin (1998) and one of our two models, respectively, $K_{1}$ and $K_{2}$ are the corresponding numbers of parameters, and $\Phi$ is the standard normal cumulative distribution function. If $z$ equals the difference in $\bar{\rho}^{2}$ values observed from Table

3 , that is, $z \approx 0.0009$, the upper bound $\Phi\left(-\sqrt{-2 z \ln L_{0}+\left(K_{2}-K_{1}\right)}\right)$ is smaller than 0.001. This provides strong evidence that our two consumption specifications perform better than the specification of Ailawadi and Neslin (1998). Further, the out-of-sample log-likelihood values in Table 3 show that the model of Ailawadi and Neslin is also outperformed in the hold-out sample.

\section{Conclusion}

In this paper, we proposed a dynamic utility maximization model for product category consumption, which is directly based on economic theory. The resulting consumption function is flexible and parameter estimates can easily be obtained. We compared our consumption specification with a related model which contains a more ad hoc based specification. For the considered data, we found that our model gives an improvement of fit, both in and out of sample.

An important subsequent research topic consists of incorporating our consumption function into a single utility framework for both category purchase and consumption behavior. This would amount to an extension of the important study of Chintagunta (1993), who considers optimal purchase behavior, but ignores optimal consumption behavior. Further, it would be interesting to develop a consumption model for two complementary product categories. 


\section{Appendix A}

The optimization problem

$$
\begin{aligned}
& \max _{\left\{C_{i, s}\right\}_{s=t}^{t+T_{i, t}}} \sum_{s=t}^{t+T_{i, t}} \frac{1}{(1+\rho)^{s-t}} u\left(C_{i, s}\right), \quad u\left(C_{i, s}\right)=\frac{C_{i, s}{ }^{1-\theta}}{1-\theta}, \\
& \text { subject to } \quad \sum_{s=t}^{t+T_{i, t}} C_{i, s} \leq S_{i, t} \text {, }
\end{aligned}
$$

can be solved using the Euler equation approach. The Lagrangian is defined by

$$
\mathcal{L}=\sum_{s=t}^{t+T_{i, t}}\left[\frac{1}{(1+\rho)^{s-t}} \frac{C_{i, s}{ }^{1-\theta}}{1-\theta}\right]-\lambda\left[\sum_{s=t}^{t+T_{i, t}} C_{i, s}-S_{i, t}\right],
$$

where $\lambda$ denotes the "shadow price" of inventory. The first-order conditions at time $s$ and time $s-1, s=t+1, t+2, \ldots, t+T_{i, t}$, are given by

$$
\begin{aligned}
\frac{1}{(1+\rho)^{s-t}} C_{i, s}^{-\theta} & =\lambda, \\
\frac{1}{(1+\rho)^{s-t-1}} C_{i, s-1}^{-\theta} & =\lambda,
\end{aligned}
$$

respectively. It immediately follows from (28) and (29) that

$$
\frac{1}{(1+\rho)^{s-t}} C_{i, s}^{-\theta}=\frac{1}{(1+\rho)^{s-t-1}} C_{i, s-1}^{-\theta}
$$

which can be rewritten as

$$
C_{i, s}=\nu C_{i, s-1} \quad \text { with } \quad \nu=(1+\rho)^{-\frac{1}{\theta}} .
$$

Condition (31) describes the dynamics of the optimal consumption path, where $\nu$ is the dampening factor. Following this consumption path, total consumption until the planning horizon equals

$$
\sum_{s=t}^{t+T_{i, t}} C_{i, s}=C_{i, t} \sum_{s=0}^{T_{i, t}} \nu^{s}=C_{i, t} \frac{1-\nu^{T_{i, t}+1}}{1-\nu} \quad \text { with } \quad \nu=(1+\rho)^{-\frac{1}{\theta}}
$$

for given current consumption $C_{i, t}$. Next, we note that the inventory restriction (26) is binding, as utility is strictly increasing in consumption, that is, more consumption always gives higher utility. Substituting (32) into the inventory restriction, and some rewriting, gives consumption $C_{i, t}$ as a function of available inventory $S_{i, t}$ and the planning horizon $T_{i, t}$, that is,

$$
C_{i, t}=S_{i, t} \frac{1-\nu}{1-\nu^{T_{i, t}+1}} \quad \text { with } \quad \nu=(1+\rho)^{-\frac{1}{\theta}} .
$$




\section{Appendix B}

Our consumption function, given by

$$
C(S, \bar{C})=S \frac{1-\nu}{1-\nu^{\frac{\exp \left(M^{\prime} \delta\right) S+\bar{C}}{\bar{C}}}} \quad \text { with } \quad \nu=(1+\rho)^{-\frac{1}{\theta}} \in(0,1),
$$

where we drop the subscripts for notational convenience, is increasing in the inventory level $S$. This can be understood from considering

$$
\begin{aligned}
\frac{\partial C(S, \bar{C})}{\partial S} & =\frac{(1-\nu)\left[\bar{C}\left(1-\nu^{\frac{\exp \left(M^{\prime} \delta\right) S+\bar{C}}{\bar{C}}}\right)+\exp \left(M^{\prime} \delta\right) S \ln (\nu) \nu^{\frac{\exp \left(M^{\prime} \delta\right) S+\bar{C}}{\bar{C}}}\right]}{\bar{C}\left(1-\nu^{\frac{\exp \left(M^{\prime} \delta\right) S+\bar{C}}{\bar{C}}}\right)^{2}}>0 \\
& \Leftrightarrow \bar{C}\left(1-\nu^{\frac{\exp \left(M^{\prime} \delta\right) S+\bar{C}}{\bar{C}}}\right)+\exp \left(M^{\prime} \delta\right) S \ln (\nu) \nu^{\frac{\exp \left(M^{\prime} \delta\right) S+\bar{C}}{\bar{C}}}>0 \\
& \Leftrightarrow \bar{C}-\left[\bar{C}-\exp \left(M^{\prime} \delta\right) S \ln (\nu)\right] \nu^{\frac{\exp \left(M^{\prime} \delta\right) S+\bar{C}}{\bar{C}}}>0 \\
& \Leftrightarrow \nu^{\frac{\exp \left(M^{\prime} \delta\right) S+\bar{C}}{\bar{C}}}<\frac{\bar{C}}{\bar{C}-\exp \left(M^{\prime} \delta\right) S \ln (\nu)} \\
& \Leftrightarrow \nu^{-\left(\frac{\exp \left(M^{\prime} \delta\right) S+\bar{C}}{\bar{C}}\right)}>\frac{\bar{C}-\exp \left(M^{\prime} \delta\right) S \ln (\nu)}{\bar{C}} \\
& \Leftrightarrow \nu^{-1} \nu^{-\frac{\exp \left(M^{\prime} \delta\right) S}{\bar{C}}}>1+\ln \left(\nu^{\left.-\frac{\exp \left(M^{\prime} \delta\right) S}{\bar{C}}\right)}\right.
\end{aligned}
$$

As $\nu^{-1}>1$, a sufficient condition is given by

$$
x>1+\ln (x) \quad \text { with } \quad x \equiv \nu^{-\frac{\exp \left(M^{\prime} \delta\right) S}{\bar{C}}}>1 .
$$

This condition is satisfied, as $x>1+\ln (x)$ holds for all $x>1$.

Next, our consumption function is also increasing in the household's average consumption rate $\bar{C}$, as we can easily verify that

$$
\frac{\partial C(S, \bar{C})}{\partial \bar{C}}=-\frac{\frac{\exp \left(M^{\prime} \delta\right) S^{2}}{\bar{C}^{2}}(1-\nu) \ln (\nu) \nu^{\frac{\exp \left(M^{\prime} \delta\right) S+\bar{C}}{\bar{C}}}}{\left(1-\nu^{\frac{\exp \left(M^{\prime} \delta\right) S+\bar{C}}{\bar{C}}}\right)^{2}}>0
$$

always holds. 
Table 1: Response parameter estimates obtained using our consumption specification with promotion anticipation effects (left), our consumption specification without promotion anticipation effects (middle), and the consumption specification of Ailawadi and Neslin (right). The standard errors are given in parentheses.

\begin{tabular}{|c|c|c|c|}
\hline & our cons.+ & our cons. & A\&N cons. \\
\hline \multicolumn{4}{|l|}{ brand choice } \\
\hline \multirow[t]{2}{*}{ brand loyalty $^{a}$} & $0.394^{* * *}$ & & \\
\hline & $(0.015)$ & & \\
\hline \multirow[t]{2}{*}{ price } & $-0.655^{* * *}$ & & \\
\hline & $(0.092)$ & & \\
\hline \multirow[t]{2}{*}{ promotion } & $0.689^{* * *}$ & & \\
\hline & $(0.233)$ & & \\
\hline \multicolumn{4}{|l|}{ purchase incidence } \\
\hline \multirow[t]{2}{*}{ inventory in dev. } & $-0.518^{* * *}$ & $-0.476^{* * *}$ & $-0.604^{* * *}$ \\
\hline & $(0.068)$ & $(0.061)$ & $(0.092)$ \\
\hline \multirow[t]{2}{*}{ category value } & $0.326^{* * *}$ & $0.320^{* * *}$ & $0.321^{* * *}$ \\
\hline & $(0.054)$ & $(0.054)$ & $(0.054)$ \\
\hline \multirow[t]{2}{*}{ lagged incidence } & $1.473^{* * *}$ & $1.504^{* * *}$ & $1.549^{* * *}$ \\
\hline & $(0.094)$ & $(0.096)$ & $(0.096)$ \\
\hline \multirow[t]{2}{*}{ avg. consumption } & $0.177^{* * *}$ & $0.170^{* * *}$ & $0.180^{* * *}$ \\
\hline & $(0.020)$ & $(0.020)$ & $(0.020)$ \\
\hline \multicolumn{4}{|l|}{ purchase quantity } \\
\hline \multirow[t]{2}{*}{ inventory in dev. } & $-0.045^{* *}$ & $-0.046^{* *}$ & $-0.062^{* *}$ \\
\hline & $(0.019)$ & $(0.016)$ & $(0.026)$ \\
\hline \multirow[t]{2}{*}{ avg. quantity } & $0.165^{* * *}$ & $0.162^{* * *}$ & $0.167^{* * *}$ \\
\hline & $(0.007)$ & $(0.007)$ & $(0.007)$ \\
\hline \multirow[t]{2}{*}{ price } & $-0.068^{* * *}$ & $-0.069^{* * *}$ & $-0.067^{* * *}$ \\
\hline & $(0.009)$ & $(0.009)$ & $(0.009)$ \\
\hline \multirow[t]{2}{*}{ promotion } & $-0.261^{* * *}$ & $-0.260^{* * *}$ & $-0.259^{* * *}$ \\
\hline & $(0.069)$ & $(0.069)$ & $(0.069)$ \\
\hline
\end{tabular}


Table 2: Estimates of consumption parameters obtained using our consumption specification with promotion anticipation effects (left), our consumption specification without promotion anticipation effects (middle), and the consumption specification of Ailawadi and Neslin (right). The standard errors for the parameters in the planning horizon are given in parentheses.

\begin{tabular}{lccc}
\hline & our cons. + & our cons. & A\&N cons. \\
\hline$\phi$ & & & -0.775 \\
$\nu$ & 0.800 & 0.804 & \\
planning horizon: intercept & -0.175 & 0.046 & \\
& $(0.619)$ & $(0.357)$ & \\
planning horizon: price & $-2.166^{*}$ & & \\
& $(1.125)$ & & \\
planning horizon: promotion & 0.455 & & \\
& $(0.321)$ & & \\
& & & \\
& &
\end{tabular}


Table 3: In-sample and out-of-sample log-likelihood values (decomposed by purchase incidence and purchase quantity), and the adjusted likelihood ratio index $\left(\bar{\rho}^{2}\right)$.

\begin{tabular}{lrcc}
\hline & our cons. + & our cons. & A\&N cons. \\
\hline in-sample & & & \\
purchase incidence & -2396.73 & -2400.23 & -2404.04 \\
purchase quantity & -1911.57 & -1910.29 & -1911.88 \\
overall & -4308.30 & -4310.52 & -4315.93 \\
$\bar{\rho}^{2}$ a & 0.1346 & 0.1346 & 0.1337 \\
\hline out-of-sample & & & \\
purchase incidence & -462.78 & -462.44 & -467.87 \\
purchase quantity & -266.71 & -266.85 & -266.75 \\
overall & -729.49 & -729.30 & -734.62 \\
\hline
\end{tabular}

$a$ : The null model has log-likelihood value -4994.75 . 


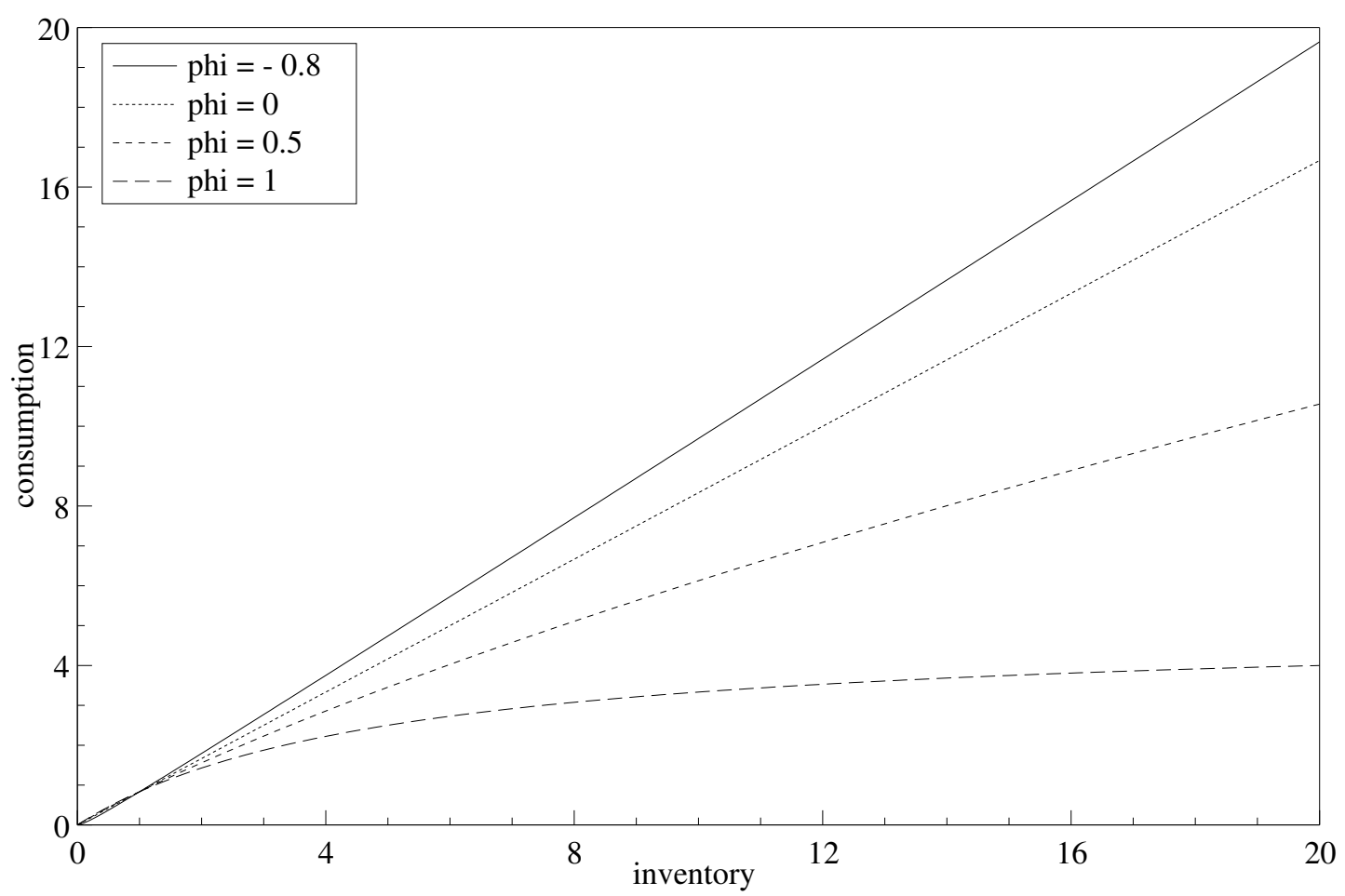

Figure 1: The consumption function of Ailawadi and Neslin (1998) for a household with an average consumption rate $\bar{C}_{i}=5$ for different parameter values $\phi$. 


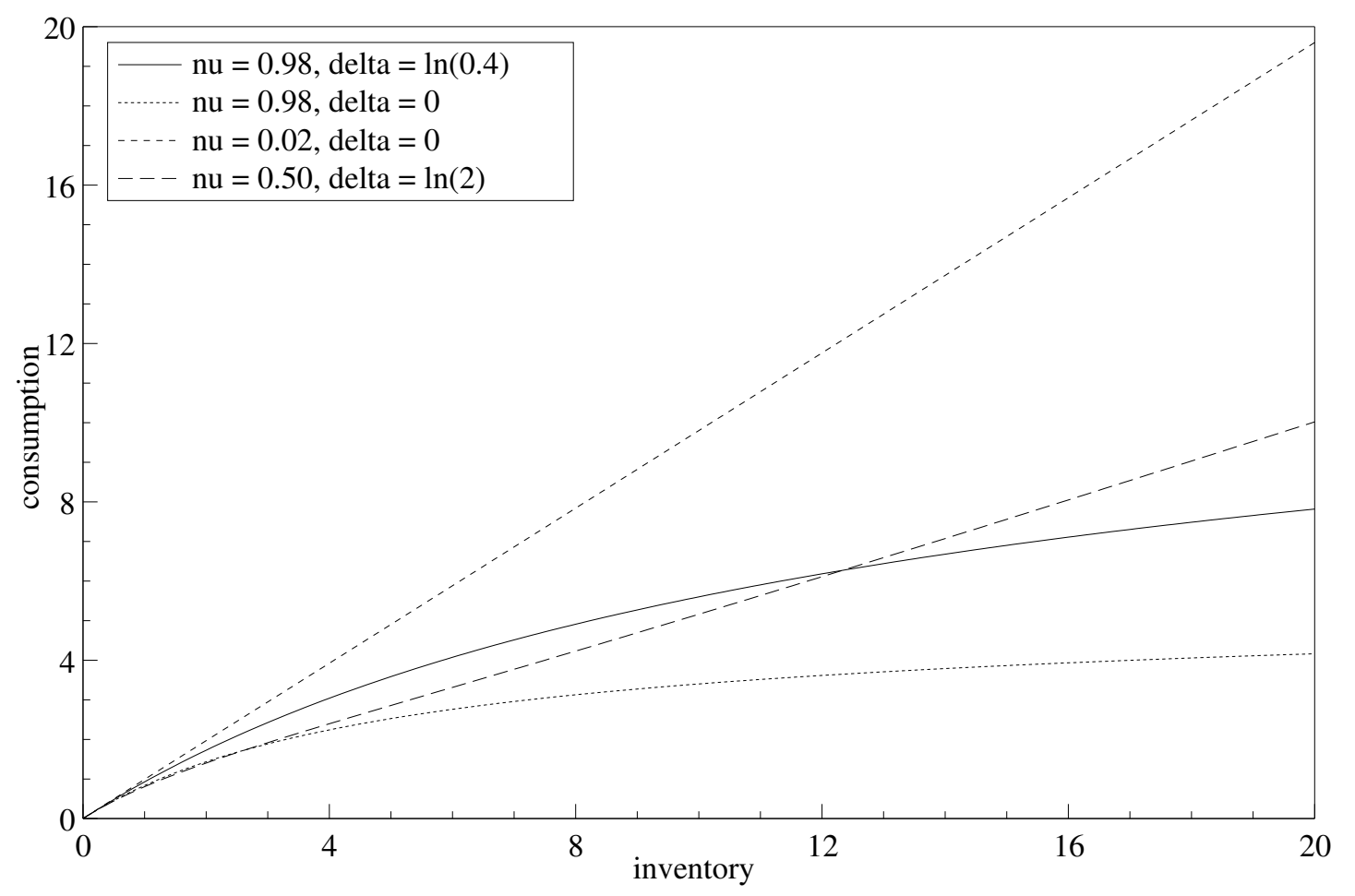

Figure 2: Our consumption function (with only one parameter $\delta$ in the planning horizon) for a household with an average consumption rate $\bar{C}_{i}=5$ for different parameter values $\nu$ and $\delta$. 


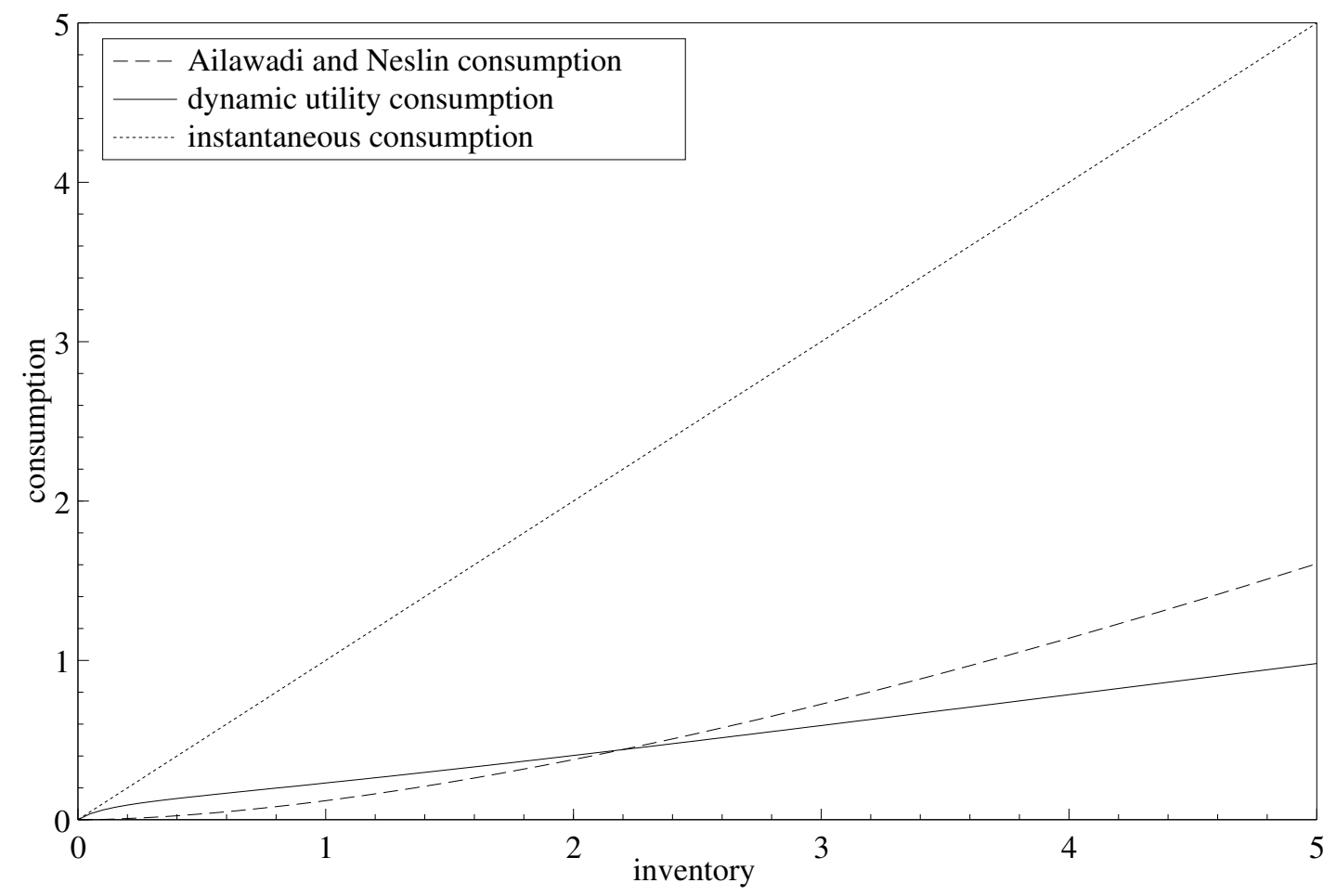

Figure 3: The estimated consumption functions, that is, the consumption specification of Ailawadi and Neslin (1998) and our dynamic utility consumption specification. For illustrative purposes, the instantaneous consumption line (consumption $=$ inventory) is also shown. 


\section{References}

Ailawadi K.L. and S.A. Neslin (1998), "The Effect of Promotion on Consumption: Buying More and Consuming It Faster", Journal of Marketing Research, 35 (August), $390-398$.

Ben-Akiva M. and S.R. Lerman (1985), Discrete Choice Analysis, Cambridge, MA: MIT Press.

Bucklin R.E. and S. Gupta (1992), "Brand Choice, Purchase Incidence, and Segmentation: An Integrated Modeling Approach", Journal of Marketing Research, 29 (May), 201-215.

Bucklin R.E., S. Gupta and S. Siddarth (1998), "Determining Segmentation in Sales Response Across Consumer Purchase Behaviors", Journal of Marketing Research, 35 (May), 189-197.

Chintagunta P.K. (1993), "Investigating Purchase Incidence, Brand Choice and Purchase Quantity Decisions of Households", Marketing Science, 12 (2), 184-208.

Doornik J.A. (1998), Object-Oriented Matrix Programming using Ox 2.0, Timberlake Consultants, London, http://www.nuff.ox.ac.uk/Users/Doornik.

Gönül F. and K. Srinivasan (1996), "Estimating the Impact of Consumer Expectations of Coupons on Purchase Behavior: A Dynamic Structural Model", Marketing Science, 15 (3), 262-279.

Guadagni P.M. and J.D.C. Little (1983), " A Logit Model of Brand Choice Calibrated on Scanner Data", Marketing Science, 2 (3), 203-238.

Gupta S. (1988), "Impact of Sales Promotions on When, What, and How Much to Buy", Journal of Marketing Research, 25 (November), 342-355.

McFadden D. (1973), "Conditional Logit Analysis of Qualitative Choice Behavior", in P. Zarembka (ed.), Frontiers in Econometrics, Chapter 4, Academic Press. 
Mela C.F., K. Jedidi and D. Bowman (1998), "The Long-Term Impact of Promotions on Consumer Stockpiling Behavior", Journal of Marketing Research, 35 (May), $250-262$.

Neslin S.A., C. Henderson and J. Quelch (1985), "Consumer Promotions and the Acceleration of Product Purchases", Marketing Science, 4 (2), 147-165.

Romer D. (1996), Advanced Macroeconomics, McGraw-Hill. 